Clinical Research Paper

\title{
Effect of Amygdalus scoparia kernel oil consumption on lipid profile of the patients with dyslipidemia: a randomized, open- label controlled clinical trial
}

\author{
Mohammad Javad Zibaeenezhad ${ }^{1}$, Maryam Shahamat ${ }^{1,2,3}$, Seyed Hamdollah \\ Mosavat ${ }^{4}$, Armin Attar ${ }^{5}$ and Ehsan Bahramali ${ }^{6}$ \\ ${ }^{1}$ Cardiovascular Research Center, School of Medicine, Shiraz University of Medical Sciences, Shiraz, Iran \\ ${ }^{2}$ Department of Cardiovascular Medicine, School of Medicine, Yasuj University of Medical Sciences, Yasuj, Iran \\ ${ }^{3}$ Student Research Committee, Shiraz University of Medical Sciences, Shiraz, Iran \\ ${ }^{4}$ Research Center for Traditional Medicine and History of Medicine, Shiraz University of Medical Sciences, Shiraz, Iran \\ ${ }^{5}$ Cardiovascular Research Center, TAHA Clinical Trial Group, Shiraz University of Medical Sciences, Shiraz, Iran \\ ${ }^{6}$ Noncommunicable Diseases Research Center, Fasa University of Medical Sciences, Fasa, Iran \\ Correspondence to: Ehsan Bahramali, email: ebahramali@fums.ac.ir \\ Armin Attar, email: attarar@sums.ac.ir
}

Keywords: Amygdalus scoparia, dyslipidemia, nuts, nutrition, traditional medicine

Abbreviations: CVD: cardiovascular disease; CAD: coronary artery disease; ASK: Amygdalus scoparia kernel; LDL: low density lipoprotein; HDL: high density lipoprotein.

Received: January 12, $2017 \quad$ Accepted: May 22, $2017 \quad$ Published: July 04, 2017

Copyright: Zibaeenezhad et al. This is an open-access article distributed under the terms of the Creative Commons Attribution License 3.0 (CC BY 3.0), which permits unrestricted use, distribution, and reproduction in any medium, provided the original author and source are credited.

\section{ABSTRACT}

Background: Amygdalus scoparia kernel (ASK) oil is traditionally used for Hyperlipidemia. Compared to olive oil, it has higher proportion of unsaturated to saturated fatty acid besides exhibiting higher index of oxidative stability. The lipidlowering effects of ASK oil however, has not been investigated yet. This study is the first one to evaluate such effects in patients with dyslipidemia.

Results: Serum triglyceride levels significantly decreased in the intervention compared to control group ( $24.80 \pm 51.70$ vs $3.13 \pm 44.80$, $p$-value $=0.03)$. Serum total cholesterol, LDL and HDL cholesterol levels did not change significantly $(p=0.28$ and $p=0.68$ and $p=0.10$ respectively).

Materials and Methods: In a double arm, open-label, randomized controlled trial,101 hyperlipidemic patients were recruited. The designation of hyperlipidemia was upon meeting either of the three criteria: having serum low-density lipoprotein (LDL) cholesterol level 130-190 (mg/dI), serum triglyceride level 150-400 $(\mathrm{mg} / \mathrm{dl})$, and serum high-density lipoprotein (HDL) cholesterol level less than $50(\mathbf{m g} / \mathrm{dl})$ for women and $40(\mathrm{mg} / \mathrm{dl})$ for men. Patients who have ever been prescribed with an antihyperlipidemic medication were excluded. They were randomly assigned to intervention group, receiving the ASK oil, for $\mathbf{6 0}$ days and control group. Serum lipid measurements were repeated at the end of the intervention period.

Conclusions: ASK oil supplementation may have a positive effect in reducing serum triglyceride level in patients with dyslipidemia without significant effect on serum cholesterol levels.

\section{INTRODUCTION}

Cardiovascular diseases (CVD) are collectively the most important chronic diseases leading to morbidity in the world and are the leading cause of death in many countries [1].
Previous reports showed that more than $30 \%$ of the population are affected with CVD [2], and coronary artery disease (CAD) accounts for the highest mortality [3]. Among the conventional $\mathrm{CV}$ risk factors, dyslipidemia is a major one $[4,5]$ which frequently coexists with metabolic syndrome $[6,7]$. 
Management of dyslipidemia has proven effects to decrease the CAD risk and morbidity [8]. Therapeutic strategies for dyslipidemia ranges from patient's lifestyle modifications to drug therapy. Dietary alterations as one of the most effective components of life style modification scheme, has been reported to be largely beneficial in CAD prevention [9]. Besides, herbal dietary supplements are becoming increasingly popular among patients with dyslipidemia [10]. Although there are some clinical trials on effectiveness of these herbs and dietary supplements but still there are lack of enough investigation on many others [11, 12].

It is now well documented that nuts can improve blood lipid profile and reduces the risk of CAD and especially walnut is shown to have lipid lowering and antihypertensive effects [13-15]. Almond and its products are also among the popular dietary supplements used in the treatment of dyslipidemia and some previous studies had shown efficacy of almond on reducing plasma triglyceride, total and low density lipoprotein (LDL) cholesterol [16]. Amygdalus scoparia, a wild species of almond that grows in large quantities in many parts of Iran and other Middle Eastern countries, is frequently used by people for nutritional and medicinal purposes. In the only study looking for the constituents of Amygdalus scoparia, the chemical analysis of the oil extract by means of gas-liquid chromatography method has revealed a high proportion of unsaturated to saturated fatty acids (7.50) compared to olive oil (4.61), along with a high index of oxidative stability [17]. It had larger proportions of C18:1 and C18:2 and smaller proportions of $\mathrm{C} 16: 0$ and C18:0 fatty acids which reveals the smaller saturated fatty acid content of Amygdalus scoparia oil compared to that of the olive oil. Clinically however, there is no evidence on the efficacy of consuming this almond's species extracts for dyslipidemia. Since the high proportion of unsaturated fatty acids in nuts generally, has been documented to have a positive effect on lipid profile of patients, we aimed to evaluate the effects of Amygdalus scoparia kernel (ASK) oil in particular, on lipid profile of the patients with dyslipidemia in a randomized, open-label controlled clinical trial.

\section{RESULTS}

From May 2014 to April 2015, a total of 172 patients were assessed for eligibility. Among the 161 who met the inclusion criteria, 52 patients refused to participate in the trial and finally 109 patients were included in the study. Randomly 54 of them were allocated to intervention group and 55 patients were allocated to control group. Figure 1 is a flow diagram of the enrolment process, groups' allocation, interventions, follow up, and analysis of the results. In the intervention group, two patients discontinued ASK oil because of distention and nausea and were excluded from the study. Moreover, one participant become pregnant and another one started using lipid lowering agents and were therefore excluded. Among the control group, two participants left the study and two started statins and were excluded.

The mean age of participants was $46.5 \pm 11.4$ and $47.2 \pm 12.3$ years in intervention and control groups, respectively $(p=0.74)$. The baseline clinical characteristics of the patients in both groups are shown in Table 1.

Mean serum triglyceride, total cholesterol and LDL cholesterol levels in addition to total cholesterol to HDL ratio decreased significantly in the intervention group compared to baseline, while no significant change was observed in HDL and non-HDL cholesterol levels (Table 2).

In the control group, the mean level of serum LDL cholesterol (119.14 \pm 20.60 vs. $111.69 \pm 24.72 \mathrm{mg} / \mathrm{dL} p=0.008)$ and non-HDL cholesterol decreased significantly compared to baseline values. However, no significant changes were observed in serum levels of triglyceride, total cholesterol, HDL cholesterol and total cholesterol to HDL ratio in this group (Table 2).

Comparison of the changes in outcomes between intervention and control groups showed a significant reduction in level of triglyceride in participants using ASK oil compared to control group $(24.80 \pm 51.70$ vs $3.13 \pm 44.80$, $p$-value $=0.03)$. However, there was no significant difference in other outcomes (Table 2).

\section{Safety and tolerability}

Two patients presented with symptoms of distention and nausea by consumption of ASK oil that discontinued oil use.

\section{DISCUSSION}

The results of this study showed that Amygdalus scoparia oil supplementation can affect lipid profile favorably particularly in reducing serum triglycerides. This is the first clinical trial to document the positive lipid lowering effects of ASK oil and confirms a well-known reputation of this product in Persian traditional medicine.

Although there are not previous animal or human studies on the effect of Amygdalus scoparia on dyslipidemia, the observed effects are in agreement with the studies on nuts oil supplementation in dyslipidemia $[5,18,19]$ where they have consistently reported positive effects on lipid profile [20]. Epidemiologic and clinical trial evidence have demonstrated multiple beneficial effects of nuts and biological mechanisms underlying such effects have been suggested. Walnuts for example are shown to improve lipid profile in hyperlipidemic patients [21,22] and its oil supplementation is reported to reduce triglycerides [23]. Jamshed and Gilani showed that almonds also, inhibit dyslipidemia in animal models through multiple pathways including inhibition of de novo cholesterol synthesis [19]. Reports on the effects of nuts on clinical outcomes are numerous. Prevention from CAD, diabetes and sudden death associated with short term feeding trials, have been attributed to rich unsaturated 
fatty acid constituents of nuts [24]. Some potential mechanisms for lipid lowering effects of unsaturated fatty acids involve the decrease in cholesterol absorption and synthesis and increase in excretion of neutral and acidic steroids [25]. They also promote transfer of cholesterol from plasma to tissues, alter the cholesterolto-protein ratio in LDL and change the rates of synthesis or catabolism of individual lipoproteins [25]. It is also showed that replacement of saturated fats by unsaturated fatty acids restores LDL-receptor affinity and decreases LDL-cholesterol concentrations [24]. Furthermore, long chain polyunsaturated fatty acids have been associated with increase in expression of genes that result in resistance to cardiac ischemia [26]. They also decrease cardiomyocyte insulin resistance and improve endothelial function along with inhibition of vascular smooth muscle cell proliferation which can ameliorate atherosclerosis process and lead to plaque stability [27].

Amygdalus scoparia has a high content of unsaturated fatty acids [17] so that the ASK oil unsaturated to saturated fatty acid ratio is nearly twice as the olive oil. Seafood consumption which has been associated with a reduced risk of primary cardiac arrest is shown to increase cell membrane unsaturated fatty acid content so that a proportion increase from $3.3 \%$ to $5 \%$ of total fatty acids was associated with $70 \%$ reduction in the risk of primary cardiac arrest [28]. Mediterranean diet which is rich in olive oil and nuts including almonds, also brings about cell membrane structural alterations. Polyunsaturated fatty acid content of cell membrane has been only modified by

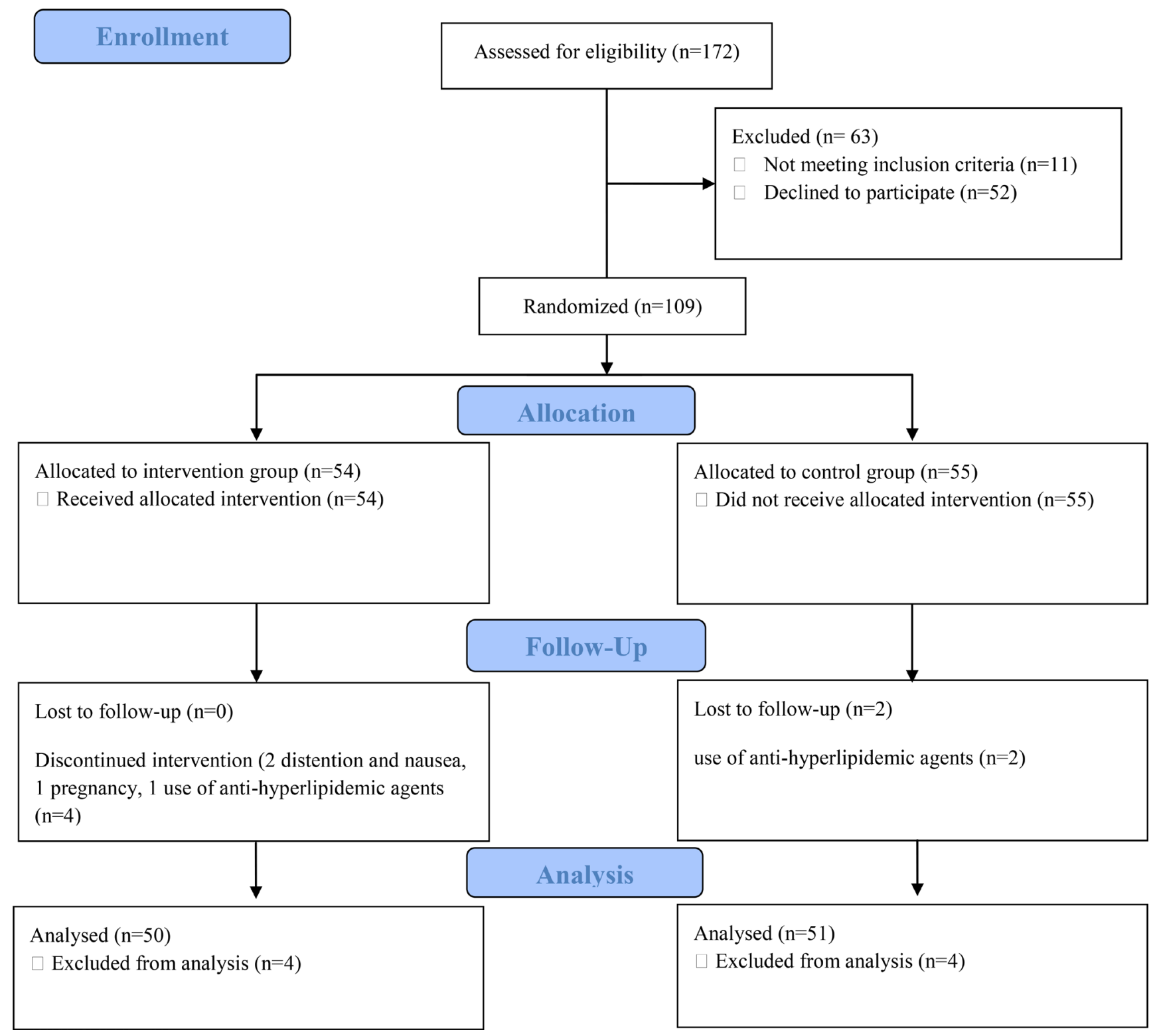

Figure 1: CONSORT Flow diagram of the enrolment, groups' allocation, interventions, follow up, and analysis of results. 
Table 1: Demographic data and baseline clinical measurements of the patient in intervention and control group

\begin{tabular}{|l|c|c|c|}
\hline \multicolumn{1}{c|}{ Basic characteristics } & Intervention group $(\boldsymbol{n}=\mathbf{5 0})$ & Control group $(\boldsymbol{n}=\mathbf{5 1})$ & $\boldsymbol{P}$-value \\
\hline Mean age (years) & $46.5 \pm 11.4$ & $47.2 \pm 12.3$ & 0.74 \\
\hline Mean body mass index $\left(\mathrm{kg} / \mathrm{m}^{2}\right)$ & $26.9 \pm 4.3$ & $27.4 \pm 2.8$ & 0.49 \\
\hline Systolic blood pressure $(\mathrm{mmHg})$ & $123.1 \pm 16.1$ & $121.1 \pm 14.5$ & 0.49 \\
\hline Diastolic blood pressure $(\mathrm{mmHg})$ & $74.8 \pm 9$ & $73.6 \pm 12$ & 0.55 \\
\hline
\end{tabular}

Table 2: Mean values (Mean \pm SD) for lipids levels in intervention and control groups before and after the study

\begin{tabular}{|c|c|c|c|c|c|c|c|c|c|c|c|}
\hline \multirow{2}{*}{ Lipid Parameters } & \multicolumn{3}{|c|}{ Intervention group } & \multirow{2}{*}{$\begin{array}{c}P \\
\text { value* }^{*}\end{array}$} & \multicolumn{3}{|c|}{ Control group } & \multirow{2}{*}{$\begin{array}{c}P \\
\text { value* }\end{array}$} & \multirow{2}{*}{$\begin{array}{c}\text { Treatment } \\
\text { effect }\end{array}$} & \multirow{2}{*}{$\begin{array}{c}95 \% \\
\text { confidence } \\
\text { interval }\end{array}$} & \multirow{2}{*}{$\begin{array}{c}P \\
\text { value }^{\dagger}\end{array}$} \\
\hline & Before & After & Difference & & Before & After & Difference & & & & \\
\hline Triglyceride (mg/dL) & $230.71 \pm 79.94$ & $205.91 \pm 83.28$ & $24.80 \pm 51.70$ & 0.002 & $183.97 \pm 54.51$ & $180.84 \pm 67.27$ & $3.13 \pm 44.80$ & 0.645 & -21.66 & -42.06 to -1.26 & 0.03 \\
\hline Total cholesterol (mg/dL) & $237.51 \pm 38.61$ & $224.57 \pm 41.58$ & $12.93 \pm 28.93$ & 0.004 & $221.76 \pm 31.36$ & $215.02 \pm 42.34$ & $6.74 \pm 26.63$ & 0.089 & -6.19 & -17.58 to 5.20 & 0.28 \\
\hline Low density lipoproteins (mg/dL) & $121.28 \pm 22.88$ & $115.28 \pm 23.32$ & $6.00 \pm 16.26$ & 0.013 & $119.14 \pm 20.60$ & $111.69 \pm 24.72$ & $7.44 \pm 18.69$ & 0.008 & 1.44 & -5.57 to 8.47 & 0.68 \\
\hline High density lipoproteins (mg/dL) & $49.54 \pm 9.71$ & $50.78 \pm 9.23$ & $-1.23 \pm 6.24$ & 0.192 & $54.00 \pm 12.83$ & $53.04 \pm 11.51$ & $0.95 \pm 6.47$ & 0.316 & 2.19 & -.044 to 4.83 & 0.10 \\
\hline Non-HDL cholestrol & $188.15 \pm 33.96$ & $173.59 \pm 37.97$ & $14.56 \pm 27.27$ & 0.122 & $169.60 \pm 29.73$ & $163.34 \pm 40.01$ & $6.25 \pm 25.00$ & 0.001 & -8.31 & -19.67 to 3.05 & 0.15 \\
\hline Total cholesterol to HDL ratio & $4.84 \pm 0.72$ & $4.48 \pm 0.73$ & $0.35 \pm 057$ & $<0.001$ & $4.38 \pm 0.94$ & $4.19 \pm 0.83$ & $0.18 \pm 0.67$ & 0.080 & -0.17 & -0.43 to 0.09 & 0.21 \\
\hline
\end{tabular}

"Shows the significance level for changes in means in each group (intervention and control) before and after 60 days.

'Shows the significance level for changes in means between the intervention and control groups after 60 days.

Mediterranean diet plus nuts compared with a low fat diet in a randomized clinical trial [29]. The same favorable outcome can be anticipated with ASK oil as well however, this probable dual benefit remains to be addressed in another study that looks for cellular structural changes secondary to ASK oil consumption.

With the current study's findings and regarding the oxidative stability of ASK oil [17], it can be proposed as a proper dietary substitute for other cooking oils, however longer follow up periods to investigate the long term cardiovascular effects of this herbal remedy in Persian traditional medicine is warranted for a definite conclusion.

One important limitation of this study was that despite randomization, we observed a significant change in some parameters of the lipid profile in the control group, especially LDL cholesterol. This can be the result of dietary discretion to consume less fat and subtle life style modification of participants after being told that they have been diagnosed with hyperlipidemia. Although we asked participants to continue their regular daily habits and maintain their diet consistent, a lack of dietary and physical activity documentation during the study by means of specific tools like food frequency and physical activity questionnaires, renders minor uncertainty to our interpretations. In addition, we didn't control for the economic and social differences which might be present across the participants. Socioeconomic determinants could influence the lifestyle and dietary habits of participants at baseline and during the intervention, though randomization minimized its effects.

\section{MATERIALS AND METHODS}

\section{Study design}

This study is a double arm, open-label, randomized controlled clinical trial that was registered by Iranian Registry of Clinical Trials with the code: IRCT201411121525N3. The study was also approved by Local Medical Ethics Committee of Shiraz University of Medical Sciences (approval number: 7191). The final goal was to evaluate the effect of ASK oil on lipid profile of the patients with dyslipidemia.

\section{Participants}

Men and women aged 20 to 70 years with LDL cholesterol level 130-190 (mg/dl), and/or triglyceride 150-400 (mg/dl), and/or high-density lipoprotein (HDL) cholesterol level less than $50(\mathrm{mg} / \mathrm{dl})$ in women and less than $40(\mathrm{mg} / \mathrm{dl})$ in men who were not taking lipid lowering medications were enrolled. Participants were selected among those referred to Shiraz Heart Health House as volunteers. They all received instructions by a cardiologist and signed an informed consent form of participation in the study.

Exclusion criteria were history of ischemic heart disease, renal, liver and thyroid disease, history of diabetes mellitus, history of food allergy especially to soya, peanuts and walnuts, history of asthma or atopic dermatitis, pregnancy and lactation, taking oral contraceptive pills 
and alcohol consumption. During the intervention period, we asked participants not to use any other lipid lowering drugs or alter their routine dietary and exercise habits. Those hospitalized during the study or developing diarrhea more than 5 episodes per day were subsequently excluded.

\section{Intervention}

Patients were randomly assigned to receive either ASK oil, as the intervention group, or without intervention as the control group in a period of two months. They were asked to refrain from consumption of Amygdalus scoparia-containing foods, vitamin supplements and herbal preparations two weeks before starting the study (as washout period). Enrolled patients received cans containing one liter of cold pressed ASK oil, produced by Mashhad plants oil industrial unit, and were asked to consume $10 \mathrm{cc}$ per day orally for 60 days. Chemical analysis of the extracted oil was as follow: oleic acid, $72.7 \%$; palmitic acid, $10.4 \%$; linoleic acid, $10.3 \%$; stearic acid, 6.1\%; palmeolytic acid, 0.3\%; gadoleic acid, $0.1 \%$ and arachidonic acid, $0.1 \%$. The overall lipid content was $39.1 \pm 1 \%$, protein content, $6 \pm 1 \%$ and water $37.6 \pm 0.2 \%$. In order to reduce errors in consumed oil dose, the disposable plastic cups with capacity of $10 \mathrm{cc}$ were provided for the patients and they were asked to take a cup of the ASK oil in daily food.

\section{Randomization}

Randomization was done using a computer-based random digit generator based on the registration number of the patients (on the order of referral). Only the statisticians were blind to the allocation of the patients.

\section{Outcome}

Serum lipid profile including total, LDL, HDL, nonHDL cholesterol levels, total cholesterol to HDL ratio, and triglyceride levels were determined at the baseline and 60 days after the intervention.

\section{Measurements}

The serum triglyceride was measured by GPO-PAP method providing a normal upper limit of $200 \mathrm{mg} / \mathrm{dL}$ (2.3 $\mathrm{mmol} / \mathrm{L})$. The total cholesterol was also checked by CHOD/PAP technique, which provided an upper limit normal value of $220 \mathrm{mg} / \mathrm{dL}(5.6 \mathrm{mmol} / \mathrm{L})$. The HDL cholesterol was measured by dextran magnesium sulfate. The LDL cholesterol was derived according to the following formula: $\mathrm{LDL}=$ total cholesterol $-(\mathrm{HDL}$ $+\mathrm{TG} / 5)[30]$.

\section{Statistical analysis}

The sample size was calculated by considering significance level of $5 \%$ and $95 \%$ power and by considering probable $10 \%$ drop-out rate; the sample size was calculated to be 55 patients in each group. Gathered data were analyzed using Statistical Package for the Social Sciences (SPSS) software (Version: 15). Statistics are represented by mean \pm standard deviation (SD). Chi square paired, and independent Samples $t$ test were conducted for data analysis as the gathered data were normally distributed with equal variances. The significance level less than 0.05 was considered in all cases.

\section{CONCLUSIONS}

It can be concluded that ASK oil supplementation may have positive effects on control of triglyceride in patients with dyslipidemia, and may be beneficial as a supplement or dietary intervention for patients with hypertriglyceridemia.

\section{ACKNOWLEDGMENTS}

The authors would like to thank Dr. Nasrin Shokrpour at Center for Development of Clinical Research of Nemazee Hospital for editorial assistance.

\section{CONFLICTS OF INTEREST}

Authors declare that there are no conflicts of interests.

\section{FUNDING}

This investigation is the result of a graduation thesis supported by grant number 7191 from vice-chancellery of research in Shiraz University of Medical Sciences.

\section{REFERENCES}

1. Alwan A. Global status report on noncommunicable diseases 2010: World Health Organization. 2011.

2. Hatmi Z, Tahvildari S, Motlag AG, Kashani AS. Prevalence of coronary artery disease risk factors in Iran: a population based survey. BMC Cardiovasc Disord. 2007; 7:1.

3. Bhatnagar P, Wickramasinghe K, Williams J, Rayner M, Townsend N. The epidemiology of cardiovascular disease in the UK 2014. Heart. 2015; 101:1182-9.

4. Khashayar P, Mohagheghi A. The correlation between dyslipidemia and coronary artery disease based on angiographic findings in an Iranian population. Acta Med Indones. 2010; 42:82-5.

5. Assari S, Ahmadi K, Saleh DK. Gender differences in the association between lipid profile and sexual function among patients with coronary artery disease. Int Cardiovasc Res J. 2014; 8:9-14.

6. Karimi F, Jahandideh D, Dabbaghmanesh M, Fattahi M, Omrani GR. The prevalence of metabolic syndrome and its 
components among adults in a rural community, Fars, Iran. Int Cardiovasc Res J. 2015; 9:94-9.

7. Eftekhari MH, Sohrabi Z, Parsa N, Zibaeenezhad MJ. Role of Gender in the Prevalence of Metabolic Syndrome and Its Related Risk Factors in Shiraz Healthy Heart Center Population. Int Cardiovasc Res J. 2015; 9:231-7.

8. Law MR, Wald NJ, Thompson S. By how much and how quickly does reduction in serum cholesterol concentration lower risk of ischaemic heart disease? BMJ. 1994; 308:367-72.

9. $\mathrm{Hu} \mathrm{FB}$, Willett WC. Optimal diets for prevention of coronary heart disease. JAMA. 2002; 288:2569-78.

10. Yeh GY, Davis RB, Phillips RS. Use of complementary therapies in patients with cardiovascular disease. Am J Cardiol. 2006; 98:673-80.

11. Khosravi Maharlooei M, Attar A, Goran A, Amuee S, Dehghan A, Monabati A. Hydatid Cyst of Ovary: A Case Report. Iran J Med Sci. 2009; 34:76-9.

12. Fugh-Berman A. Herbs and dietary supplements in the prevention and treatment of cardiovascular disease. Prev Cardiol. 2000; 3:24-32.

13. Abbey M, Noakes M, Belling GB, Nestel PJ. Partial replacement of saturated fatty acids with almonds or walnuts lowers total plasma cholesterol and low-densitylipoprotein cholesterol. Am J Clin Nutr. 1994; 59:995-9.

14. Sabate J, Fraser GE. Nuts: a new protective food against coronary heart disease. Curr Opin Lipidol. 1994; 5:11-6.

15. Sabate ̌̌ J, Campero B, Casals E, Merlos M, Laguna JC, Ros E. Substituting walnuts for monounsaturated fat improves the serum lipid profile of hypercholesterolemic men and women: a randomized crossover trial. Ann Intern Med. 2000; 132:538-46.

16. Hyson DA, Schneeman BO, Davis PA. Almonds and almond oil have similar effects on plasma lipids and LDL oxidation in healthy men and women. J Nutr. 2002; 132:703-7.

17. Farhoosh R, Tavakoli J. Physicochemical properties of kernel oil from Amygdalusscoparia growing wild in Iran. J Food Biochem. 2008; 15:433-43.

18. Huguenin GV, Oliveira GM, Moreira AS, Saint'Pierre TD, Gonçalves RA, Pinheiro-Mulder AR, Teodoro AJ, Luiz RR, Rosa G. Improvement of antioxidant status after Brazil nut intake in hypertensive and dyslipidemic subjects. Nutr J. 2015; 14:1.

19. Jamshed H, Gilani AH. Almonds inhibit dyslipidemia and vascular dysfunction in rats through multiple pathways. J Nutr. 2014; 144:1768-74.

20. Ranjbar-Zahedani M, Alinejad N, Zadeh SMA, Mazloom Z. Comparison of the Effects of Edible Oils: Rice Bran, Grape Seed, and Canola on Serum Lipid Profile and Paraoxonase Activity in Hyperlipidemic Rats. Int Cardiovasc Res J. 2015; 9:28-33.
21. Zambón D, Sabaté J, Munoz S, Campero B, Casals E, Merlos M, Laguna JC, Ros E. Substituting walnuts for monounsaturated fat improves the serum lipid profile of hypercholesterolemic men and womena randomized crossover trial. Ann Intern Med. 2000; 132:538-46.

22. Zibaeenezhad M, Shamsnia S, Khorasani M. Walnut consumption in hyperlipidemic patients. Angiology. 2005; $56: 581-3$.

23. Zibaeenezhad MJ, Farhadi P, Attar A, Mosleh A, Amirmoezi F, Azimi A. Effects of walnut oil on lipid profiles in hyperlipidemic type 2 diabetic patients: a randomized, double-blind, placebo-controlled trial. Nutr Diabetes. 2017; 7:e259.

24. Kris-Etherton PM, Pearson TA, Wan Y, Hargrove RL, Moriarty K, Fishell V, Etherton TD. High-monounsaturated fatty acid diets lower both plasma cholesterol and triacylglycerol concentrations. Am J Clin Nutr. 1999; 70:1009-15.

25. Goodnight SH, Harris WS, Connor WE, Illingworth D. Polyunsaturated fatty acids, hyperlipidemia, and thrombosis. Arteriosclerosis. 1982; 2:87-113.

26. Shysh AM, Nagibin VS, Kaplinskii SP, Dosenko VE. N-3 long chain polyunsaturated fatty acids increase the expression of PPAR $\gamma$-target genes and resistance of isolated heart and cultured cardiomyocytes to ischemic injury. Pharmacol Rep. 2016; 68:1133-9.

27. Perdomo L, Beneit N, Otero YF, Escribano Ó, DíazCastroverde S, Gómez-Hernández A, Benito M. Protective role of oleic acid against cardiovascular insulin resistance and in the early and late cellular atherosclerotic process. Cardiovasc Diabetol. 2015; 14:75.

28. Siscovick DS, Raghunathan T, King I, Weinmann S, Wicklund KG, Albright J, Bovbjerg V, Arbogast P, Smith H, Kushi LH. Dietary intake and cell membrane levels of longchain n-3 polyunsaturated fatty acids and the risk of primary cardiac arrest. Jama. 1995; 274:1363-7.

29. Barceló F, Perona JS, Prades J, Funari SS, Gomez-Gracia E, Conde M, Estruch R, Ruiz-Gutiérrez V. MediterraneanStyle Diet Effect on the Structural Properties of the Erythrocyte Cell Membrane of Hypertensive Patients ThePrevencion con DietaMediterranea Study. Hypertension. 2009; 54:1143-50.

30. Warnick GR, Knopp RH, Fitzpatrick V, Branson L. Estimating low-density lipoprotein cholesterol by the Friedewald equation is adequate for classifying patients on the basis of nationally recommended cutpoints. Clin Chem. $1990 ; 36: 15-9$. 